Verónica de la T. Oropeza C Cadernos Prolam/USP, v.16, n.30, p.42-72, jan./jun.2017

\title{
LAS ELITES EN MÉXICO: SU ARRIBO, CIRCULACIÓN Y DESEMPEÑO EN LOS AÑNS 80 Y 90
}

THE ELITES IN MEXICO: HIS ARRIVAL, CIRCULATION AND PERFORMANCE IN THE 1980s AND 1990s

Verónica de la Torre Oropeza ${ }^{1}$ Universidad Nacional Autónoma de México, Cidade do México, México.

Resumen: Estudiamos al grupo de tecnócratas que ocuparon los cargos más altos de las principales instituciones de gobierno entre 1980 y 1990. ¿Cómo entran, circulan y salen de la elite del poder? Retomamos el criterio de elite del poder de Wright Mills y de John Scott dada la importancia de las instituciones donde este se ejerce y dondese toman las decisiones trascendentales del país. Adscribimos la idea paretiana de circulación de las elites porque encaja con algunas características de quienes ingresan a la elite del poder. También, es útil para entender ciertas prácticas antidemocráticas de la clase política para mantenerse en el poder.

Palabras clave: elites políticas; circulación; elite del poder; tecnócratas.

\begin{abstract}
We focus on the group of technocrats who held the highest positions of the main governmental institutions between 1980 and 1990. How do they enter, circulate within and leaving from elite of power? We return to the power elite theories of Wright Mills and John Scott due to the importance of the institutions where power lies and where the country's momentous decisions are made. We use Pareto's idea of circulation of elites because it fits with some features of those who enter to the power elite. It is also useful to understand certain antidemocratic practices used by the political class in order to stay in power.
\end{abstract}

Key words: political elites; circulation; power elite; techocrats.

\footnotetext{
${ }^{1}$ Doctora en Estudios Iberoamericanos por la Universidad Complutense de Madrid, Maestra en Relaciones Internacionales por la Universidad Nacional Autónoma de México. E-mail: orodelatorre@ hotmail.com.
} 


\section{INTRODUCCIÓN}

En México es significativa aquella aseveración que TheEconomist hizo en enero de 2015 al presidente Peña Nieto, “A president who doesn't get that he doesn't get it”, "Un presidente que no entiende que no entiende" (trad. propia). Esto con relación a los problemas de corrupción en los que el presidente y su gabinete pudieron haber incurrido hace unos años. Sin embargo, el no captar o aparentar que no se sabe sobre determinados asuntos o problemáticas, puede significar, entre otras cosas, no querer ir a la raíz de éstas o ignorar todo lo concerniente a las mismas. 'No entienden que no entienden', es aplicable a gran parte de la clase política, a su comportamiento, a los valores y mentalidad con los que entran, circulan y se sostienen en el sistema político.

En el marco de lo anterior, este trabajo se centra en el grupo de tecnócratas ${ }^{2}$ que ocuparon los cargos más alto de las principales instituciones de gobierno entre 1980 y 1990, en cómo se convirtieron en la elite del poder, en la importancia de los lazos de parentesco y amistad. Se optó por el criterio de elite del poder de Wright Mills (1956) y de Scott (2008) porque es en las principales instituciones del Estado donde se lleva acabo el ejercicio del poder y la toma de decisiones trascendentales para el país. De otra parte, el concepto circulación de las elites, de Pareto en concreto, es útil para analizar las prácticas antidemocráticas de gran parte de la clase política mexicana, como el patrimonialismo, las relaciones de amiguismo, compadrazgo y una empecinada mentalidad de enriquecerse por medio de la política. Estos (anti) valores se muestran a la vez como impedimento para una circulación, entendida como renovación, que a la vez conduzca hacia un régimen razonablemente democrático.

Al contrario de la idea de Pareto (1980), "la circulación de las elites en México implica la permanencia o continuidad en el poder político de altos funcionarios, sus hijos, parientes o amigos, como si fuera una circulación dirigida desde posiciones de poder”.

\footnotetext{
${ }^{2}$ De acuerdo con varios autores (Silva, 1997; Joignant, 2009; Domínguez y Feinberg, 1997) el tecnó'crata es alguien con expertise en un campo técnico, alguien experto en economía, por ejemplo. Más abajo nos referiremos al technopol, es quien, además de contar con la técnica, también tiene habilidades políticas, cierta experiencia en política mediante un cargo público, o un puesto de elección. Ejemplos de technopols son Carlos Salinas de Gortari y su núcleo interno conformado por Córdoba Montoya, Pedro Aspe, Zedillo, entre otros. A partir del periodo de Miguel de la Madrid los tecnócratas arriban a más cargos públicos. Con Salinas su número incrementó y el tecnócrata José Ángel Gurría fue nombrado Canciller, relegando así a gente del Servicio Exterior Mexicano.
} 
En México quienes principalmente investigan sobre el comportamiento de las elites políticas y económicas son los periodistas. Es de reconocer que los periodistas, aun con el riesgo que implica su profesión en ese país, sobre todo si denuncian enriquecimiento vía corrupción, abuso de poder e impunidad, son quienes han hecho en los últimos 20 años una suerte de radiografía del comportamiento y valores de la clase política ${ }^{3}$ y empresarial. ${ }^{4}$ Todos estos son trabajos periodísticos valiosos que traslucen una preocupación sociológica por los diversos efectos que dichas conductas tienen sobre el sistema político y sobre la sociedad.

Los orígenes de la clase política mexicana tienen sus raíces en la 'familia revolucionaria', o en la figura del político tradicional creada por el Partido Revolucionario Institucional (PRI) a partir del gobierno de Miguel Alemán (1946-1952). El Partido fue la escuela principal de los políticos hasta los años 70; en esa década los jóvenes priístas empezaron a salir, a Estados Unidos principalmente, a hacer estudios de postgrado, de ahí que Roderic Camp (2006) se haya referido a la figura del 'político híbrido', como alguien que posee características del político tradicional, como ser abogado de provincia y que adoptó la ortodoxia neoliberal de los tecnócratas de los años 80. Estos últimos, han fungido hasta hoy como correas de transmisión ideológica y son quienes pusieron en marcha las reformas neoliberales más radicales. Las personas mencionadas en la tabla de abajo en su mayoría representan un cambio generacional e ideológico en el nuevo contexto del paradigma neoliberal, en este caso al interior de la clase política y del régimen político mexicano. Es una generación que rompió con el ápice de nacionalismo, demagógico o no, del político y tecnócrata tradicional, para hacer converger sus intereses con las exigencias del capitalismo global comandado por Estados Unidos principalmente.

\section{EL HISTÓRICO DESACUERDO ENTRE LAS ELITES}

\footnotetext{
${ }^{3}$ Por clase política entendemos al conjunto de hombres y mujeres que se desempeña profesionalmente en cargos públicos de elección y de alta dirección, en las principales instancias del Estado y a nivel federal, empezando por el poder ejecutivo, el legislativo, el judicial; las dirigencias de los partidos políticos, sindicatos, etc. Mediante la 'clase empresarial' abarcamos a todos los empresarios en todos sus niveles de importancia (comerciantes, empresarios, banqueros, industriales, agroexportadores). La elite económica sólo se refiere a quienes tienen un alto peso en la economía, como C. Slim, A. Baillères, L. Zambrano (CEMEX), la familia Vázquez Raña, etc.

${ }^{4}$ Entre los últimos trabajos periodísticos está el libro de Diego Osorno Slim. Biografía política del mexicano más rico del mundo (2015); el de Ricardo Raphael Mirreynato (2014); de Francisco Cruz Jiménez Los juniors del poder (2014).

${ }^{5}$ En el libro de F. BrandenburgTheMakingModerMexico (1964) quedó acuñada esta denominación clave.
} 
Unos años antes de morir Camacho Solís, quien fue miembro de la elite en el periodo abordado, escribió un libro donde la pregunta guía es el porqué de la persistencia del desacuerdo entre la clase política, así como sus efectos nocivos para el desarrollo socioeconómico del país. Un desacuerdo construido socialmente, que lleva implícita la confrontación y el estilo de hacer política suma ceroentre dicha clase política. Es así que las Constituciones de 1857 y de 1917 significaron la victoria de un grupo sobre otro $^{6}$, en un contexto de enormes desigualdades sociales en el que los privilegios y los intereses desde entonces no han podido ser moderados ni reformados jurídicamente (CAMACHO SOLÍS, 2006).

Esto último nos recuerda la tesis de Burton y colaboradores (1992) descrita en 'El método de llegar a un acuerdo'. Los autores argumentan que donde hay elites capaces de construir consensos y llegar acuerdos incluyentes, se consigue avanzar y consolidar regímenes democráticos. De modo que regímenes con democracias [aparentemente] estables pero deficitarias, suelen caracterizarse por la presencia de elites desunidas, con un modo de hacer política como proceso de negociación donde el interés público gane. Aunque la tesis de Burton es elitista, no excluye al resto de los actores como la sociedad misma; argumenta que los acuerdos entre elites son necesarios para alcanzar y desarrollar un régimen democrático. Sin embargo, estas elites también generan pactos, no acuerdos, que obstaculizan o posponen la democratización de un régimen ${ }^{7}$. En México los pactos entre la elite del poder en turno son un quid pro quo y por lo tanto son de corto plazo, son excluyentes, porque lo que se pacta no es en beneficio del bien común. El último de este tipo es el Pacto por México de 2012 que principalmente sacaría adelante las reformas estructurales en materia de energía y telecomunicaciones que estuvieron estancadas desde el gobierno de Vicente Fox.

El reconocido historiador de México, Alan Knight, en su capítulo publicado en la edición de Higley y Gunther (1992), analizó a las elites mexicanas del periodo entre Calles y Obregón, particularmente el año de crisis entre 1928 y 1929 tras el asesinato de este último. Knight se interesó en cómo fue el proceso de negociación, el tipo de pacto alcanzado, sus características, el tipo de elite $y$, en perspectiva, si esto traería una subsecuente democratización (1992:..). La

\footnotetext{
${ }^{6}$ Knight la denominó 'competición darwiniana o hobbesiana', dentro de la misma 'familia revolucionaria', parientes ideológicos perdidos por una codicia fratricida por el poder (1992:131)

${ }^{7}$ Edgardo Buscaglia lleva años refiriéndose a que existe un pacto de impunidad en la clase política de este país. Véase: Lavado de Dinero y corrupción política (2015).
} 
conclusión a la que él llega todavía tiene eco en la actualidad: "Cuando las elites nacionales participan en México pactan las ventajas de las elites sobre las masas y también las ventajas del centro contra las provincias. Las negociaciones por lo tanto proclaman la estabilidad del gobierno y la centralización del poder" (KNIGHT, 1992, p. 129). Acerca de la estabilidad que el pacto entre diversas facciones de las elites posrevolucionarias trajo entre 1928 y 1929, Knight(1992) opina que éste había servido para mantener atrincherados los intereses de las elites y para atajar cualquier indicio de democratización. Este estudio alcanza a los gobiernos de MMH y de CSG que en palabras de Knight"supeditaron y atajaron la liberalización política a favor de la económica, y que el modo cómo la hicieron requirió del reforzamiento del estilo autoritario del régimen" (KNIGHT, 1992, p.136).

\section{LA GENERACIÓN DE TECNÓCRATAS EN EL PERIODO DE REFERENCIA}

Es importante hacer referencia al grupo de jóvenes que realizaron estudios de posgrado en economía y gobierno principalmente, porque ellos se convirtieron en la elite que emprendió la radical restructuración de la economía mexicana, de modo supeditado y acorde con la doctrina neoliberal y los intereses del capital estadounidense. Varios de estos jóvenes eran hijos o parientes de gente que había sido parte de la elite política en gobiernos anteriores, pero también hubo otros que provenían de la clase trabajadora como Zedillo. Ellos fueron parte de los reformadores tecnócratas gracias a sus relaciones y mentores. Varios de éstos desde su juventud estaban afiliados al Partido Revolucionario Institucional (PRI), y quienes no, tuvieron que hacerlo. Habían hecho estudio de postgrado fuera del país y regresaron hacia finales de 1970 a ocupar posiciones de mando en instituciones estratégicas, principalmente en las secretarías de Programación y Presupuesto y la de Hacienda, de las que salían los presidentes desde José López Portillo (1976-1982) ${ }^{8}$. De acuerdo con Babb (2005) y Teichman (1995), la promoción de los programas de postgrado de Estados Unidos no sólo la hicieron académicos estadounidenses o personajes como Nelson Rockefeller o la Fundación Ford, sino también, como señala Babb, hubo apegos ideológicos dentro de los países de América Latina, existentes antes de esas promociones

\footnotetext{
${ }^{8}$ Hay varios estudios críticos en torno a los tecnócratas y technopols de los años 80 y 90 egresados del círculo de universidades famosas conocido como el Ivy League, entre estos tenemos a Miguel Ángel Centeno, 1994; a Sara Babb, 2005; a Judith Teichman, 1995; 2001).
} 
y mucho antes de que el neoliberalismo se asentara como paradigma dominante ${ }^{9}$, esas filias provenían de los mentores del grupo estudiado.

De ahí que la variable 'estudios de postgrado en el extranjero’ y su dimensión ideológica sea relevante en los años 70 cuando la ortodoxia neoliberal llega a las principales universidades estadounidenses. Hacer estudios en el extranjero es clave porque ahí se forjan y consolidan las redes que dan acceso a la elite política ${ }^{10}$. Estudiar en alguna institución del Ivy League ${ }^{11}$, condujo a estos jóvenes a conocer gente del ámbito académico, empresarial y político de 'clase global' (Teichman, 2001; Sassen, 2007). A la mayoría de quienes citamos en este trabajo les aseguró volver al país a ocupar un alto cargo público. El grupo de elite consolidado por Carlos Salinas de Gortari con gente que conoció fuera y la de su grupo cercano en México ${ }^{12}$, sería el que llevaría a cabo las reformas neoliberales requeridas conforme a las necesidades del modo de producción capitalista y el auge del capitalismo financiero global del último tercio del siglo XX.

La tabla que sigue a continuación enlista los principales cargos públicos en los dos sexenios referidos estas son la Presidencia, la Secretaría de Programación y Presupuesto ${ }^{13}$, Banco de México y Hacienda (Teichman, 1995, p. 43; Camp, 2006, p. 254; Rousseau, 1998, p. 339). Algunos de ellos provenían de familias que habían sido parte de la elite política tiempo atrás en la capital del país y en provincia, como Miguel de la Madrid y Carlos Salinas de Gortari. Otros

\footnotetext{
${ }^{9}$ Una obra esclarecedora sobre el poder de las top universities es el libro de Juan Gabriel Valdés: Pinochet'sEconomists: The Chicago School in Chile, Cambridge UniversityPress, 1995.

${ }^{10}$ Esta variable por sí sola alcanza para elaborar un análisis de redes. Buena parte de quienes han conformado la elite política se conocieron fuera de México mientras hacían estudios de posgrado o diplomados simplemente. En el gobierno actual Nuño Mayer estrechó relaciones con el círculo de Peña Nieto vía Luis de Videgaray, Secretario de Hacienda, a quien conoció en Oxford Inglaterra.

${ }^{11}$ Yale, el MIT, Harvard, Chicago y Stanford son las instituciones donde más mexicanos influyentes han estudiado (Camp, 2006:202 y ss.) Esto las hace atractivas a los ojos de los jóvenes que aspiran a conseguir becas de CONACYT para hacer un posgrado en estas universidades. Camp referencia el caso de Humberto Hernández Haddad como el de la fascinación en la que caen los estudiantes, sobre todo aquellos con escaso capital cultural (Camp, 2006:203).

${ }^{12}$ El caso más significativo fue su relación con el ciudadano francés Joseph Córdoba Montoya, su Jefe de asesores, de quien Camacho Solís y otros dicen fue el 'cerebro del ajuste estructural'. Para que Córdoba asumiera el alto cargo de Jefe de la Oficina de Presidencia hubo que naturalizarlo, pero antes, a su llegada en 1979 lo primero fue afiliarlo al PRI. Para gente cercana a Carlos Salinas, como el mismo Camacho Solís, él se convirtió en el poder detrás de bambalinas. Rogelio Gasca Neri, en principio un desconocido, fue otro integrante de ese grupo cuya amistad también la hizo a partir de su estancia en Estados Unidos.

${ }^{13}$ Para Teichman (1995) fue clara la trascendencia de la SPP desde López Portillo hasta 1992, tanto así que los primeros presidentes tecnócratas pasaron por ésta. En 1992 CSG decidió devolver las atribuciones de esa dependencia a la Secretaría de Hacienda. Cabe señalar que también desde MMH su 'gabinete económico,' además de incorporar a las tres dependencias clave, debido al contexto económico interno y externo, empezó a incorporar los sectores de energía y comercio en los temas del gabinete.
} 
provinieron de la clase alta como Pedro Aspe Armella, familia pudiente con antepasados en la elite política. O de clase media alta como Manuel Camacho; alguno proveniente de la clase trabajadora, como Ernesto Zedillo, que por méritos propios (beca de la Fundación Ford) realizó estudios de postgrado en el extranjero, donde forjó relaciones de amistad durante sus estudios de postgrado con gente como Salinas hasta llegar a ser presidente. Al término de su mandato su alma mater la Universidad de Yale, le nombró director del Centro de Estudios para la Globalización $^{14}$.

\begin{tabular}{|c|c|c|c|c|c|c|}
\hline Funcionario & $\begin{array}{l}\text { Condición } \\
\text { socioecon } \\
\text { ómica }\end{array}$ & $\begin{array}{l}\text { Parentescos } \\
\text { en política }\end{array}$ & $\begin{array}{l}\text { Estudios } \\
\text { de post- } \\
\text { grado }\end{array}$ & $\begin{array}{l}\text { Estudios } \\
\text { de pre- } \\
\text { grado }\end{array}$ & Mentor & $\begin{array}{l}\text { Cargo previo/ } \\
\text { periodo } \\
\text { estudiado }\end{array}$ \\
\hline $\begin{array}{l}\text { Miguel de la } \\
\text { Madrid } \\
\text { Hurtado, MMH } \\
(\mathrm{F})^{\star} \\
\text { Emilio } \\
\text { Gamboa } \\
\text { Patrón, } \\
\text { secretario } \\
\text { particular. }\end{array}$ & Media alta & $\begin{array}{l}\text { Bisabuelo } \\
\text { Miguel de la } \\
\text { Madrid } \\
\text { Guerrero, } \\
\text { gobernador de } \\
\text { Colima en la } \\
\text { década de } \\
\text { 1880; su } \\
\text { abuelo, } \\
\text { Enrique O. de } \\
\text { la Madrid, } \\
\text { también } \\
\text { gobernador en } \\
\text { dos } \\
\text { cuatrienios } \\
\text { 1903-1911 }\end{array}$ & $\begin{array}{l}\text { Maestría } \\
\text { en } \\
\text { adminis- } \\
\text { tración } \\
\text { pública } \\
\text { en } \\
\text { Harvard } \\
\text { Universi- } \\
\text { ty }\end{array}$ & $\begin{array}{l}\text { Licenciatu- } \\
\text { ra en } \\
\text { Derecho } \\
\text { en la } \\
\text { UNAM }\end{array}$ & $\begin{array}{l}\text { José } \\
\text { López } \\
\text { Portillo }\end{array}$ & $\begin{array}{l}\text { Secretario de } \\
\text { Programación y } \\
\text { presupuesto } \\
\text { (SPP) con José } \\
\text { López Portillo, } \\
\text { presidente de la } \\
\text { República }\end{array}$ \\
\hline $\begin{array}{l}\text { Carlos salinas } \\
\text { de Gortari }\end{array}$ & $\begin{array}{l}\text { Clase } \\
\text { media alta }\end{array}$ & $\begin{array}{l}\text { Su padre Raúl } \\
\text { Salinas } \\
\text { Lozano, quien } \\
\text { empezó como } \\
\text { director de } \\
\text { estudios }\end{array}$ & $\begin{array}{l}\text { Maestría } \\
\text { en } \\
\text { administr } \\
\text { ación } \\
\text { pública } \\
\text { en }\end{array}$ & \begin{tabular}{l}
\multicolumn{2}{l}{ Economía } \\
en la \\
UNAM. El \\
sínodo lo \\
integraron: \\
Jesús Silva
\end{tabular} & $\begin{array}{l}\text { Miguel } \\
\text { de la } \\
\text { Madrid }\end{array}$ & $\begin{array}{l}\text { Secretario de } \\
\text { Programación y } \\
\text { Presupuesto } \\
\text { (SPP). }\end{array}$ \\
\hline
\end{tabular}

${ }^{14}$ La tendencia a la búsqueda de lucro desmedido de parte de los grandes corporativos en el neoliberalismo ha legitimado la figura del technopol, después de que estos ocupan altos cargos públicos en sus países, con información privilegiada, se convierten en consejeros de administración de una o más corporaciones de 'clase global'. A estos renovados 'usos' se le denomina en la academia anglosajona "revolvingdoor", o la puerta giratoria. 


\begin{tabular}{|c|c|c|c|c|c|c|}
\hline${ }^{\star}$ Fallecido & & $\begin{array}{l}\text { económicos } \\
\text { en la } \\
\text { Secretaría de } \\
\text { Hacienda en } \\
1948 \text { y } 1954 . \\
\text { Luego } \\
\text { Secretario de } \\
\text { Industria y } \\
\text { comercio entre } \\
\text { 1958-1964. } \\
\text { Llegó a ser } \\
\text { considerado } \\
\text { como el } \\
\text { 'presidenciabl } \\
\text { e' en } \\
\text { gabinete de } \\
\text { López Mateos. } \\
\text { Durante el } \\
\text { sexenio de De } \\
\text { la Madrid fue } \\
\text { senador por el } \\
\text { PRI. }\end{array}$ & $\begin{array}{l}\text { Harvard } \\
(1973) \text { y } \\
\text { doctorad } \\
\text { o en } \\
\text { economí } \\
\text { a política } \\
\text { y la } \\
\text { gobierno } \\
\text { en } \\
\text { misma } \\
\text { universid } \\
\text { ad (1978) }\end{array}$ & $\begin{array}{l}\text { Herzog; } \\
\text { Hugo B. } \\
\text { Margáin; } \\
\text { Miguel de } \\
\text { la Madrid y } \\
\text { Leopoldo } \\
\text { Solís. }\end{array}$ & & \\
\hline $\begin{array}{l}\text { Joshep Marie } \\
\text { Córdoba } \\
\text { Montoya }\end{array}$ & $\begin{array}{l}\text { Nacido en } \\
\text { Francia. } \\
\text { Hijo de } \\
\text { padres } \\
\text { españoles } \\
\text { republica- } \\
\text { nos } \\
\text { exiliados. }\end{array}$ & $\begin{array}{l}\text { Los vínculos } \\
\text { que hizo con } \\
\text { Rogelio Gasca } \\
\text { Neri, Donaldo } \\
\text { Colosio, } \\
\text { Guillermo } \\
\text { Ortiz y sobre } \\
\text { todo con } \\
\text { Carlos Salinas } \\
\text { de Gortari } \\
\text { cuando todos } \\
\text { estos } \\
\text { estudiaban } \\
\text { sus } \\
\text { doctorados en } \\
\text { Estados } \\
\text { Unidos. }\end{array}$ & $\begin{array}{l}\text { Ingeniero } \\
\text { por la } \\
\text { ÉcolePol } \\
\text { ytech- } \\
\text { nique de } \\
\text { París. } \\
\text { Filosofía } \\
\text { por la } \\
\text { Soborna. }\end{array}$ & $\begin{array}{l}\text { Estudios } \\
\text { de } \\
\text { doctorado } \\
\text { en } \\
\text { Stanford, } \\
\text { no } \\
\text { concluidos. }\end{array}$ & $\begin{array}{l}\text { Sus } \\
\text { mentores } \\
\text { fueron } \\
\text { sus } \\
\text { vínculos } \\
\text { en EEUU } \\
\text { antes } \\
\text { mencion } \\
\text { ados. } \\
\text { Cuando } \\
\text { Carlos } \\
\text { Salinas } \\
\text { regresó a } \\
\text { México } \\
\text { se lo } \\
\text { trajo y se } \\
\text { naturaliz } \\
\text { ó } \\
\text { mexicano }\end{array}$ & 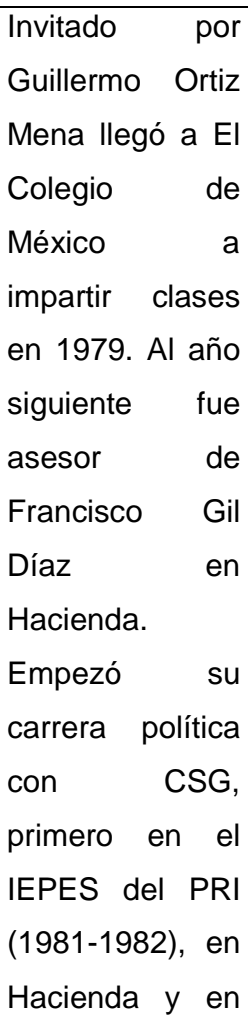 \\
\hline
\end{tabular}




\begin{tabular}{|c|c|c|c|c|c|c|}
\hline & & & & & $\begin{array}{l}\text { Zedillo } \\
\text { dedicó su } \\
\text { tesis de } \\
\text { doctorad } \\
0 \quad \text { a } \\
\text { Córdoba } \\
\text { Montoya. }\end{array}$ & $\begin{array}{l}\text { Programación y } \\
\text { Presupuesto. Se } \\
\text { nacionalizó } \\
\text { mexicano en } \\
\text { 1985. Asesor de } \\
\text { CSG durante la } \\
\text { campaña y ya } \\
\text { en la } \\
\text { presidencia éste } \\
\text { (1988) } \\
\text { nombró Jefe de } \\
\text { la Oficina de } \\
\text { Presidencia. Se } \\
\text { dice que en el } \\
\text { gabinete se le } \\
\text { conocía como } \\
\text { "el poder detrás } \\
\text { del trono". }\end{array}$ \\
\hline $\begin{array}{l}\text { Rogelio Gasca } \\
\text { Neri }\end{array}$ & $\begin{array}{l}\text { Clase } \\
\text { media }\end{array}$ & $\begin{array}{lr}\text { Su amistad } \\
\text { con el } \\
\text { de } \\
\text { hrupo } \\
\text { Estadinas } \\
\text { Unidos }\end{array}$ & $\begin{array}{l}\text { Maestría } \\
\text { en } \\
\text { administr } \\
\text { ación de } \\
\text { empresa } \\
\text { s por } \\
\text { Stanford; } \\
\text { doctorad } \\
\text { o en } \\
\text { Ciencias } \\
\text { por } \\
\text { Standford. }\end{array}$ & $\begin{array}{l}\text { Ingeniería } \\
\text { química } \\
\text { industrial } \\
\text { en el IPN. }\end{array}$ & $\begin{array}{l}\text { Sus } \\
\text { amista- } \\
\text { des en } \\
\text { Estados } \\
\text { Unidos }\end{array}$ & $\begin{array}{l}\text { Fue el último } \\
\text { secretario de } \\
\text { Programación y } \\
\text { Presupuesto en } \\
\text { el gabinete de } \\
\text { Carlos Salinas. } \\
\text { Antes había sido } \\
\text { director de } \\
\text { Sidermex, } \\
\text { director general } \\
\text { de Aeroméxico. } \\
\text { Con Zedillo fue } \\
\text { Director general } \\
\text { de la Comisión } \\
\text { Federal de } \\
\text { Electricidad. } \\
\text { Después ocupo } \\
\text { cargos fuera de } \\
\text { los círculos } \\
\text { políticos } \\
\text { centrales, como } \\
\text { director } \\
\text { Fondo del }\end{array}$ \\
\hline
\end{tabular}




\begin{tabular}{|c|c|c|c|c|c|c|}
\hline & & & & & & $\begin{array}{l}\text { Cultura } \\
\text { Económica y } \\
\text { luego Cónsul en } \\
\text { Austin. También } \\
\text { estuvo en la } \\
\text { CFE y fue } \\
\text { consejero } \\
\text { independiente } \\
\text { en PEMEX } \\
\text { hasta 2013 }\end{array}$ \\
\hline $\begin{array}{l}\text { Manuel } \\
\text { Camacho } \\
\text { Solís (F) }\end{array}$ & $\begin{array}{l}\text { Clase } \\
\text { media alta }\end{array}$ & 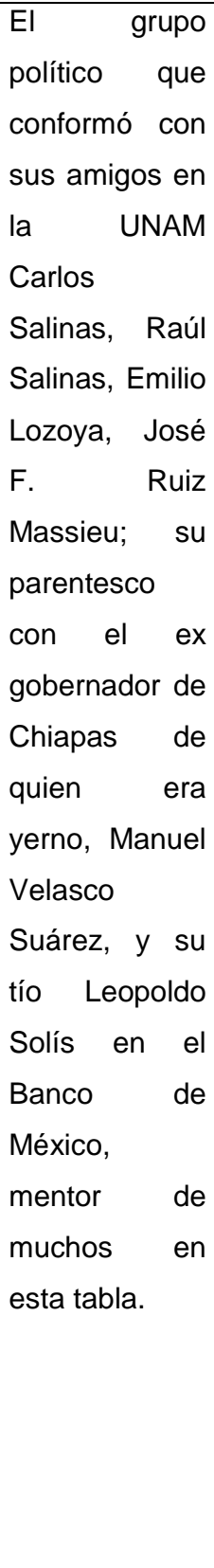 & 列 & 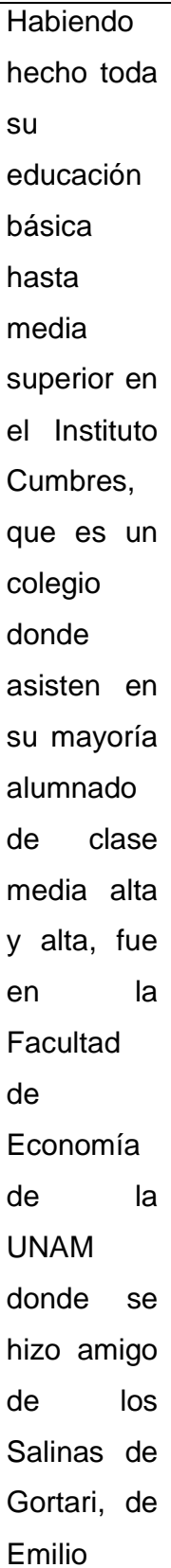 & $\begin{array}{l}\text { Con } \\
\text { Rodrigo } \\
\text { Gómez y } \\
\text { Leopoldo } \\
\text { Solís }\end{array}$ & 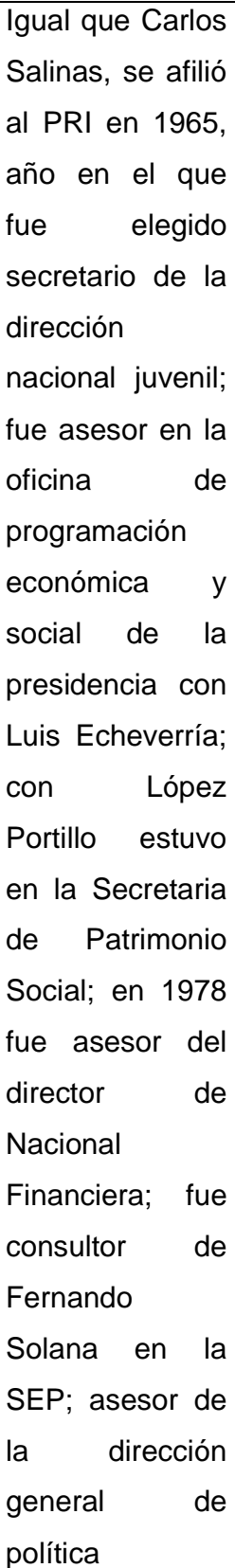 \\
\hline
\end{tabular}




\begin{tabular}{|c|c|c|c|c|c|c|}
\hline & & & & $\begin{array}{l}\text { Loyoza } \\
\text { donde } \\
\text { conoció a } \\
\text { Ruiz } \\
\text { Massieau. }\end{array}$ & & 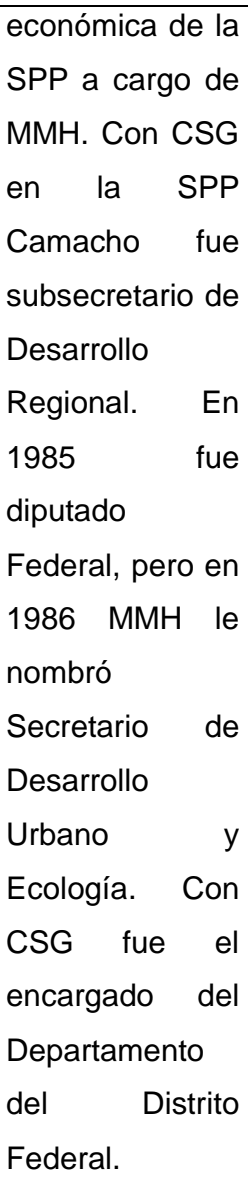 \\
\hline $\begin{array}{ll}\text { Pedro } & \text { Aspe } \\
\text { Armella } & \end{array}$ & $\begin{array}{l}\text { Clase alta. } \\
\text { Hijo de } \\
\text { Pedro } \\
\text { Aspe Sais, } \\
\text { que fue } \\
\text { director } \\
\text { general de } \\
\text { la } \\
\text { exclusiva } \\
\text { tienda } \\
\text { departame } \\
\text { ntal El } \\
\text { Palacio de } \\
\text { Hierro, y } \\
\text { profesor de } \\
\text { una } \\
\text { escuela } \\
\text { ícono de la } \\
\text { abogacía }\end{array}$ & $\begin{array}{l}\text { El origen } \\
\text { socioeconómic } \\
0 \text { de Aspe } \\
\text { Armella no se } \\
\text { enmarca en la } \\
\text { política de } \\
\text { años previos, } \\
\text { aunque su } \\
\text { bisabuelo fue } \\
\text { diputado } \\
\text { federal con } \\
\text { Porfirio Díaz y } \\
\text { su abuelo fue } \\
\text { el coordinador } \\
\text { del Servicio } \\
\text { Mexicano } \\
\text { Diplomático } \\
\text { con } \\
\text { presidente }\end{array}$ & $\begin{array}{l}\text { Doctor } \\
\text { en } \\
\text { Economí } \\
\text { a por el } \\
\text { Massach } \\
\text { usetts } \\
\text { Institute } \\
\text { of } \\
\text { Tecnnolo } \\
\text { gy } \\
\text { (1978). } \\
\text { El MIT es } \\
\text { parte del } \\
\text { Ivy } \\
\text { League, } \\
\text { y en ese } \\
\text { año } \\
\text { conoce a } \\
\text { Carlos }\end{array}$ & $\begin{array}{l}\text { Licenciatur } \\
\text { a en el } \\
\text { Instituto } \\
\text { Tecnológic } \\
\text { o } \\
\text { Autónomo } \\
\text { de México } \\
\text { (ITAM) en } \\
\text { 1974. Él es } \\
\text { el creador } \\
\text { del } \\
\text { programa } \\
\text { de la } \\
\text { economía } \\
\text { de } \quad \text { maestría } \\
\text { del ITAM. } \\
\text { Es un } \\
\text { miembro }\end{array}$ & $\begin{array}{l}\text { Francisc } \\
\text { o Gil } \\
\text { Díaz; } \\
\text { estudian- } \\
\text { te y } \\
\text { amigo de } \\
\text { Leopoldo } \\
\text { Solís, un } \\
\text { mentor } \\
\text { de } \\
\text { muchos } \\
\text { 'moneyd } \\
\text { octors', } \\
\text { tío de } \\
\text { Manuel } \\
\text { Camacho } \\
\text { Solís. }\end{array}$ & $\begin{array}{l}\text { En } 1980 \text { es } \\
\text { asesor de } \\
\text { Carlos Salinas, } \\
\text { cuandor este } \\
\text { estaba como } \\
\text { director general } \\
\text { del Instituto de } \\
\text { Estudios } \\
\text { Políticos, } \\
\text { Económicos y } \\
\text { Sociales } \\
\text { (IEEPES) del } \\
\text { PRI. Primer } \\
\text { presidente del } \\
\text { Instituto } \\
\text { Nacional } \\
\text { Estadística } \\
\text { Geografía. } \\
\text { Subsecretario }\end{array}$ \\
\hline
\end{tabular}




\begin{tabular}{|c|c|c|c|c|c|c|}
\hline & $\begin{array}{l}\text { La Escuela } \\
\text { Libre de } \\
\text { Derecho. }\end{array}$ & $\begin{array}{l}\text { Álvaro } \\
\text { Obregón. }\end{array}$ & Salinas. & $\begin{array}{l}\text { honorario } \\
\text { de dicha } \\
\text { institución, } \\
\text { él ha sido } \\
\text { el } \\
\text { diseñador } \\
\text { del plan de } \\
\text { estudios } \\
\text { de } \\
\text { economía. }\end{array}$ & & $\begin{array}{l}\text { de } \\
\text { Programación y } \\
\text { Presupuesto y } \\
\text { secretario de } \\
\text { ésta cuando } \\
\text { Carlos Salinas } \\
\text { es designado } \\
\text { candidato } \\
\text { presidencial del } \\
\text { PRI. }\end{array}$ \\
\hline $\begin{array}{l}\text { Francisco Gil } \\
\text { Díaz }\end{array}$ & $\begin{array}{l}\text { Clase } \\
\text { media/med } \\
\text { ia alta. }\end{array}$ & $\begin{array}{l}\text { Parece que no } \\
\text { tenía } \\
\text { parentescos } \\
\text { en política. }\end{array}$ & $\begin{array}{l}\text { Economí } \\
\text { a en el } \\
\text { ITAM; } \\
\text { postgrad } \\
0 \quad \text { en } \\
\text { economí } \\
\text { a en la } \\
\text { Universit } \\
\text { y of } \\
\text { Chicago. }\end{array}$ & & $\begin{array}{l}\text { Leopoldo } \\
\text { Solís, } \\
\text { mentor y } \\
\text { luego } \\
\text { jefe. }\end{array}$ & 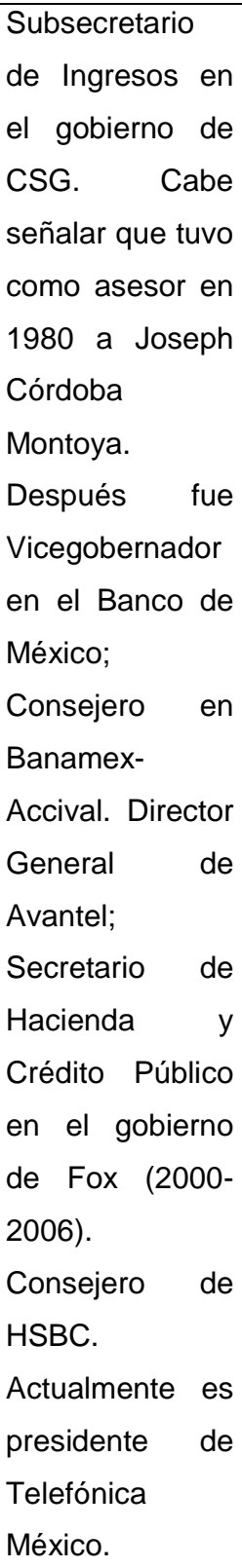 \\
\hline Miguel & Clase alta & Hijo de una & Maestría & Licenciatur & Consider & De 1958 a 1962 \\
\hline
\end{tabular}




\begin{tabular}{|c|c|c|c|c|c|c|}
\hline $\begin{array}{l}\text { Mancera } \\
\text { Aguayo }\end{array}$ & & 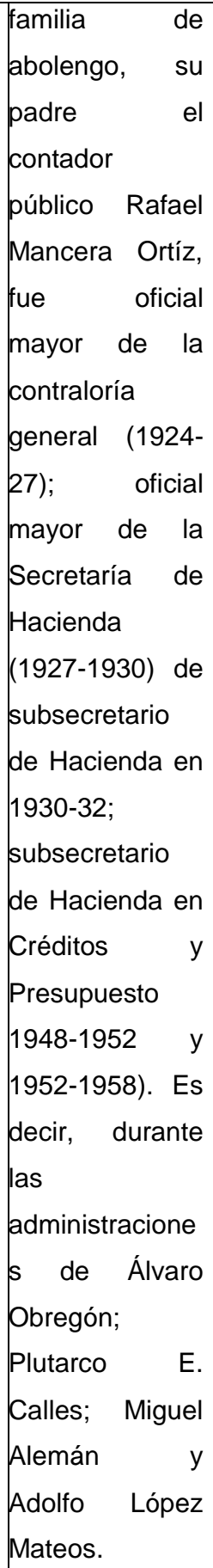 & $\begin{array}{l}\text { en } \\
\text { economí } \\
\text { a en } \\
\text { Yale, ahí } \\
\text { conoce a } \\
\text { Jesús } \\
\text { Silva } \\
\text { Herzog } \\
\text { Flores. }\end{array}$ & $\begin{array}{l}\text { a en } \\
\text { economía } \\
\text { en el } \\
\text { ITAM. }\end{array}$ & $\begin{array}{l}\text { o que } \\
\text { Rodrigo } \\
\text { Gómez, } \\
\text { pero } \\
\text { Roderic } \\
\text { Camp } \\
\text { señala a } \\
\text { Leopoldo } \\
\text { Solís, } \\
\text { también } \\
\text { como } \\
\text { mentor } \\
\text { de } \\
\text { Mancera. }\end{array}$ & $\begin{array}{l}\text { fue su primera } \\
\text { participación en } \\
\text { el Banco de } \\
\text { México. En } 1982 \\
\text { Miguel de la } \\
\text { Madrid } \\
\text { nombra director } \\
\text { general. }\end{array}$ \\
\hline $\begin{array}{lr}\text { Jesús } & \text { Silva } \\
\text { Herzog } & \text { Flores } \\
\text { (F) } & \end{array}$ & Media alta & $\begin{array}{l}\text { Hijo de un } \\
\text { célebre } \\
\text { economista y } \\
\text { catedrático a } \\
\text { quien presidió } \\
\text { la comisión } \\
\text { para el tema }\end{array}$ & $\begin{array}{l}\text { Maestría } \\
\text { en } \\
\text { economí } \\
\text { a en } \\
\text { Yale. }\end{array}$ & $\begin{array}{l}\text { Licenciatur } \\
\text { a en } \\
\text { economía } \\
\text { en la } \\
\text { UNAM }\end{array}$ & $\begin{array}{l}\text { Además } \\
\text { de su } \\
\text { padre, } \\
\text { Rodrigo } \\
\text { Gómez, } \\
\text { aunque } \\
\text { Camp }\end{array}$ & $\begin{array}{l}\text { Gerente General } \\
\text { del Banco de } \\
\text { México en 1977- } \\
\text { 1978; Secretario } \\
\text { de Hacienda en } \\
\text { el último año de } \\
\text { José López }\end{array}$ \\
\hline
\end{tabular}


Verónica de la T. Oropeza C Cadernos Prolam/USP, v.16, n.30, p.42-72, jan.jun.2017

\begin{tabular}{|c|c|c|c|c|c|c|}
\hline & & 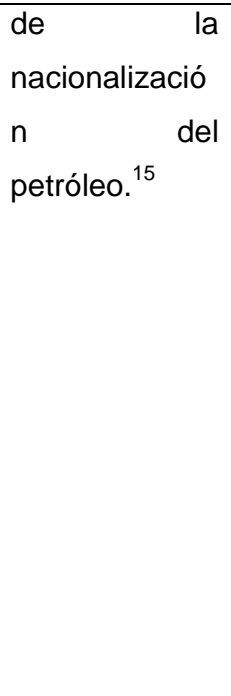 & & & $\begin{array}{l}\text { también } \\
\text { incluye a } \\
\text { Leopoldo } \\
\text { Solís. }\end{array}$ & $\begin{array}{l}\text { Portillo; } \\
\text { Secretario de } \\
\text { Hacienda con } \\
\text { Miguel de la } \\
\text { Madrid de } \\
\text { 1982- } \\
\text { 1986. } \\
\text { Salinas } \\
\text { Gortari de } \\
\text { embajador de } \\
\text { México } \\
\text { España } \\
\text { secretario } \\
\text { Turismo. }\end{array}$ \\
\hline $\begin{array}{l}\text { Ernesto Zedillo } \\
\text { Ponce de } \\
\text { León }\end{array}$ & $\begin{array}{l}\text { Clase } \\
\text { trabajadora }\end{array}$ & $\begin{array}{l}\text { Sin vínculos } \\
\text { previos. Fue } \\
\text { en la oficina } \\
\text { de } \\
\text { Presidencia } \\
\text { donde entró } \\
\text { como analista } \\
\text { (1971-1974), } \\
\text { un puesto al } \\
\text { que } \\
\text { incorporan } \\
\text { recién } \\
\text { egresados de } \\
\text { licenciatura. } \\
\text { Por medio de } \\
\text { un amigo suyo } \\
\text { conoció ahí a } \\
\text { Carlos } \\
\text { Salinas. }\end{array}$ & $\begin{array}{l}\text { Maestría } \\
\text { y } \\
\text { doctorad } \\
0 \quad \text { en } \\
\text { economí } \\
\text { a en } \\
\text { Yale. }\end{array}$ & $\begin{array}{l}\text { Licenciatur } \\
\text { a en } \\
\text { economía } \\
\text { en el } \\
\text { Instituto } \\
\text { Politécnico } \\
\text { nacional }\end{array}$ & $\begin{array}{l}\text { Leopoldo } \\
\text { Solís }\end{array}$ & $\begin{array}{l}\text { Subsecretario } \\
\text { de Planeación y } \\
\text { Control } \\
\text { Presupuestales } \\
\text { decir, con } \\
\text { Carlos Salinas } \\
\text { cuando éste } \\
\text { estaba en la } \\
\text { SPP }\end{array}$ \\
\hline $\begin{array}{ll}\text { Jaime } & \text { Serra } \\
\text { Puche } & \end{array}$ & $\begin{array}{l}\text { Clase } \\
\text { media }\end{array}$ & $\begin{array}{l}\text { Sin vínculos. } \\
\text { Sus padres } \\
\text { españoles } \\
\text { exiliados en }\end{array}$ & $\begin{array}{l}\text { Maestría } \\
\text { en } \\
\text { economí } \\
\text { a en El }\end{array}$ & $\begin{array}{l}\text { Licenciatur } \\
\text { a en } \\
\text { ciencias } \\
\text { políticas y }\end{array}$ & $\begin{array}{l}\text { Leopoldo } \\
\text { Solís }\end{array}$ & $\begin{array}{lr}\text { Secretario } & \text { de } \\
\text { Comercio } & \text { y } \\
\text { Fomento } & \\
\text { Industrial } & \end{array}$ \\
\hline
\end{tabular}

15 Jesús Silva Herzog junto a otros como Manuel Gómez Morín, Eduardo Villaseñor y Daniel Cosío Villegas impulsaron desde finales de 1920 la creación de la Escuela de Economía, primero como parte de la facultad de Derecho de la Universidad Nacional y finalmente de manera autónoma en 1935. La escasez de estudiantes en Economía permitió que los profesores de la Escuela Nacional de Economía (ENE) ocuparan altos cargos en el gobierno, de ahí la simbiosis entre profesores y estudiantes quienes al terminar sus estudios conseguían un empleo en la burocracia. 


\begin{tabular}{|l|l|l|l|l|}
\hline & México. & $\begin{array}{l}\text { Colegio } \\
\text { de } \\
\text { México; } \\
\text { doctorad } \\
\text { or en } \\
\text { economí } \\
\text { a en Yale } \\
\text { (1975- } \\
1979)\end{array}$ & $\begin{array}{l}\text { administrán en la } \\
\text { UNAM }\end{array}$ & \\
& & & $\begin{array}{l}\text { (después } \\
\text { Economía) en el } \\
\text { gabinete de } \\
\text { Salinas de } \\
\text { Gortari. Principal } \\
\text { negociador del } \\
\text { TLCAN y por 28 } \\
\text { días Secretario } \\
\text { de hacienda y } \\
\text { Crédito Público, } \\
\text { debido al 'error' } \\
\text { de diciembre de } \\
1994 .\end{array}$ \\
\hline
\end{tabular}

Quadro 1 - Responsables de las principales secretarías y despachos entre 1982 y 1994

Fuente: Elaboración de la autora.

El porcentaje de funcionarios públicos con estudios de postgrado en México y Estados Unidos desde 1970 se invirtió: 58 \% de estos había cursado un postgrado en México, un 13\% en Estados Unidos; en 1980, 48\% en México y 21\% en Estados Unidos; en 1984, 31\% en México y postgrado35\% en Estados Unidos; en 1989, 29\% en México y $48 \%$ en Estados Unidos (GALINDO, 1993 in CAMP, 2006). En 1988 la revista Expansión señalaba que el 52\% de los funcionarios de alto nivel estudiaron en el extranjero, principalmente en Estados Unidos (CAMP, 2006). Elegir este país en vez de Europa para hacer un postgrado, principalmente en economía, tuvo estrecha relación con el rol de los mentores según hemos visto en este trabajo.

Camp sostiene que Yale y el MIT tuvieron un papel crucial en la formación crítica de las futuras elites del poder que controlaron la política económica de México en las décadas de 1980 y 1990:

Con el programa de Administración Económica Internacional Yale atrajo a prominentes economistas mexicanos a su esfera intelectual desde 1953. Sólo seis integrantes de la elite del poder se graduaron en Yale, el número menor entre las cuatro escuelas de las Ivy League, pero cinco de ellos dirigieron las tres instituciones responsables de formular la política macroeconómica de México y de dar el giro hacia una estrategia ortodoxa neoliberal (CAMP, 2006, p. 207). 
Los egresados de los que habla Camp eran: Miguel Mancera Aguayo, director del Banco de México de 1982 a 1997; Jesús Silva Herzog Flores, secretario de Hacienda de 1982 a 1986; Ernesto Zedillo secretario de Programación y Presupuesto de 1988 a 1992 y Jaime Serra Puche secretario de Comercio y Fomento Industrial de 1988 a 1994 (CAMP, 2006, p.207). Como puede observarse, Leopoldo Solís fue el mentor de casi todos los que aparecen en la tabla. Solís se había graduado en Yale en 1959, después de sus estudios su desempeño profesional se dio principalmente en el BM junto a su mentor Rodrigo Gómez.

Para Sarah Babb, "la tendencia a la internacionalización de los altos mandos en el gobierno tuvo como consecuencia la 'americanización"l6 de la economía del país" (BABB, 2005, p.156). La autora argumenta que a diferencia de los ámbitos del derecho, negocios o ingeniería, los programas doctorales en ciencias sociales tienden a concentrarse en el conocimiento teórico en lugar del práctico, de ahí que:

La crisis del peso mexicano en 1994 y la debacle macroeconómica en Argentina en el 2001 ejemplifican de manera particularmente espectacular cómo los tecnócratas entrenados en economía al estilo académico estadounidense pueden resultar singularmente incapaces de manejar economías nacionales (BABB, 2005, p.157)

- También, hay que considerar que gran parte de los tecnócratas de Latinoamérica provienen de clase media, media alta y alta, es decir, vienen de sociedades segmentadas estructural y étnicamente, y buena parte de ellos desconoce la realidad socioeconómica de sus países. El panorama no es muy distinto en la elite económica. Algunos grandes empresarios, sobre todo del norte del país, estudiaron en Estados Unidos. Realmente el auge de los estudios de postgrado fuera de México se dio a partir de esta generación de tecnócratas. Eran vistos por los jóvenes clase medieros como un ejemplo de éxito. Como apunta Camp, no era una moda sino hasta una necesidad "en la medida en que los círculos de elite comenzaron a darle mayor énfasis a los títulos académicos en el extranjero (...)” (CAMP, 2006, p.197). Los hijos de los grandes empresarios no suelen pensar en esos términos porque al finalizar sus estudios de pregrado trabajarán en la empresa del padre, como es el caso de los hijos del multimillonario Carlos Slim

\footnotetext{
${ }^{16}$ La traductora del artículo de Babb aclara que el sentido de ‘americanización' en ese trabajo se refiere a la adopción de características que se consideran propias del contexto cultural y social de Estados Unidos.
} 
que estudiaron en una de las universidades exclusivas de la Ciudad México, la Universidad Anáhuac, del grupo de Los Legionarios de Cristo. Otra universidad exclusiva es la Universidad Iberoamericana, de la Compañía de Jesús, una institución reconocida por su buen nivel académico, aunque algunos estudiantes tengan padres influyentes tienen que estudiar para acreditar.

De acuerdo con Centeno (1994:191 y ss.), el grupo tecnócratas mexicanos en su paso por las universidades del Yvy League, adquieren una "ideología epistemológica", un marco cognoscitivo con un modo único de analizar problemas sociales, formular soluciones e instrumentar políticas, limitando el potencial de la participación pública y negando la inevitabilidad de los intereses en conflicto. En este sentido, Camacho Solís señalaba que los principales colaboradores del gabinete económico de Carlos Salinas eran fervientes defensores del modelo neoliberal "hasta el punto, como en el caso de Jaime Serra Puche, de la intolerancia ideológica." (CAMACHO SOLÍS, 2006, p.54). Sin embargo, estos tecnócratas no llegaron a las universidades norteamericanas como tabula rasa, como ya se dijo, detrás estuvieron sus mentores ${ }^{17}$ neoclásicos en el Banco de México, en el ITAM y en El Colegio de México, quienes elegían y se recomendaban a los mejores estudiantes para enviarlos a Estados Unidos a hacer doctorados (SOLÍS, 2012, p. 24). Los mentores más mencionados son Rodrigo Gómez y Leopoldo Solís, de algún otro modo también David Ibarra, Daniel Cosío y Víctor Urquidi. Todos ellos tenían fuertes vínculos con académicos de Estados Unidos y Europa, con gente de las fundaciones Rockefeller o Ford. Persuadían a sus mejores pupilos de estudiar economía en Estados Unidos, de adquirir 'la técnica' que en México no se enseñaba. Camp comenta que Urquidi era de 'esa elite intelectual de actuar independiente', que sin consultar a otras instancias federales se encargó de ampliar el programa permanente del Banco de México y del dialogo directo con universidades de Estados Unidos (CAMP, 2006). El propio Leopoldo Solís narró su experiencia con su mentor Rodrigo Gómez ${ }^{18}$ (SOLÍS, 2012, pp. 15-24). Aunque Camp tiene

\footnotetext{
${ }^{17}$ Para RodericAi Camp (2006:47), está claro que los mexicanos dependen de mentores destacados para alcanzar estatus de elite, este requisito continúa aplicando hasta el día de hoy, y aunque pudiera ser meritocrático en muchos casos, es al mismo tiempo un mecanismo de la circulación dirigida, de tipo patriarcal, de las elites del poder. Los mentores "son los agentes críticos en la formación de redes entre las elites del poder" (Camp, 2006:47), digamos que fueron hacedores de la elite del poder.

${ }^{18}$ En palabras de Solís, la escuela de economía de la UNAM a finales de los 40 era bastante mala, en manos de marxistas, si el alumno se declaraba marxista o estaba afiliado al partido comunistas, aprobaba exámenes sin estudiar (Cárdenas y Zabludovsky, 2012); y fue hasta 1973 cuando se creó la maestría en economía en la UNAM. El Colegio
} 
razón al señalar que Gómez fue el 'conector', intergeneracional podríamos decir, en la red de las elites (CAMP, 2006), Leopoldo Solís fue, a decir de varios que aparecen en la tabla, su maestro, mentor, jefe y gracias a sus relaciones académicas les envió a estudiar a Estados Unidos. Uno de sus pupilos que aparece en la tabla anterior, Francisco Gil Díaz, apunta con ironía en una reunión en el ITAM: "Finalmente, quiero que sepan que si hay un culpable, un responsable último de la cantidad de Chicago Boys que hay en México, es Leopoldo Solís” (GIL DÍAZ, 2012, p. 43). Gil Díaz, es un technopol de la 'puerta giratoria', fue subsecretario de Ingresos en la Secretaría de Hacienda en la administración de Carlos Salinas (1988-1994). De 1994 a 1997 fue subgobernador del Banco de México; de 1997 a 2000 director general de Avantel, cargo que dejó para ser Secretario de Hacienda con Vicente Fox. Al terminar fue asesor de HSBC y actualmente es el presidente de Telefónica en México. Y como él, Pedro Aspe o Jaime Serra, entre otros, apenas concluyen en su función pública ocupan asientos de consejero en empresas nacionales o transnacionales. Todo ello a pesar de que su mentor Solís les inculcara que fueran economistas profesionales, que siguieran el enfoque neoclásico como una metodología y no como una ideología.

\section{EXPERTISE, MANDO Y PODER EN LAS ELITES ENTRE 1980-1990}

El relevo generacional es el primero de tres aspectos mediante los que Pareto entiende la circulación de las elites. El segundo se refiere al reemplazamiento de una elite por otra, que enlaza en nuestro estudio con el primer aspecto; y el tercero se refiere a las elites y las masas (PARETO, 1980). Si bien, la circulación en Pareto supone lo contrario al estancamiento, la dinámica presente en las altas esferas de la política mexicana deja entrever un tipo de circulación 'dirigida' o con escasa renovación, porque las elites suelen reemplazarse mediante el nepotismo y amiguismo. Ejemplo de ello es que durante los dos sexenios estudiados los principales cargos los ocuparon gentes que tuvieron o tenían parentescos con funcionarios y políticos. La circulaciónparetiana también queda en entredicho cuando el grupo o fracción en el poder pacta con otro, para obstaculizar la llegada de grupos opuestos que pudieren poner en riesgo la conservación del mismo poder y la de sus privilegios. En sí, el carácter patrimonial y corporativo del régimen político mexicanoobstruye la circulación de personas e ideas nuevas. Así, es todavía

de México bajo la dirección de Cosío Villegas y Víctor Urquidi en 1961 ya habían creado el Centro de Estudios Económicos y en 1964 crearon la maestría en economía. 
evidente que las relaciones de amiguismo y compadrazgo negocian o pactan el arribo de familiares y amigos a los altos cargos burocráticos o de elección popular, con o sin requisitos meritocráticos. ${ }^{19}$

Es histórica la existencia de grupos de elite en todas las sociedades, pero el rol de éstas siempre es crucial sobre todo en sociedades con un deficiente check and balance (límites en todos los niveles de gobierno). En sociedades democráticas el poder político se caracteriza por la competencia, la eficiencia, la comunicación, la transparencia y la participación de la sociedad civil en política. En regímenes políticos como el mexicano, el acceso y ascenso a puestos de poder, y la permanencia, está fuertemente ligado a la familia y al grupo: "El poder político es asimilado entre las elites políticas mexicanas de manera casi patrimonialista, en donde la circulación de sus miembros se realiza entre las mismas familias bajo la variante de personajes y generaciones (...) Una suerte de estatus heredado" (NIETO, 2011, p.170) ${ }^{20}$. Aunque en los últimos años se empiezan a ver cambios, la circulación de las elites en el régimen mexicano ha sido una circulación dirigida, por decirlo así.

La gente que fue parte de la elite del poder entre 1980 y 1990 le tocó vivir el tránsito hacia el paradigma neoliberal del capitalismo global. Esta generación que nació en la década de los cincuenta, cuyas edades fluctuaban entre los 35 y 45 años, también provocó grietas al interior del régimen político mexicano: trataron de imponerse frente a ciertos códigos tradicionales del régimen históricamente hegemonizado por PRI, entre estos la ideología nacionalista propagada por el régimen construido después de la revolución mexicana, y la demagogia populista mediante la cual había corporativizado a la sociedad civil. En verdad, estos eran aspectos que los tecnócratas, a partir de Miguel de la Madrid, detestaban.

Finalmente, los tecnócratas, por sí mismos, no pudieron hacer frente a la clase política tradicional priísta y sus bastiones, los sindicatos corporativos de la Confederación Nacional de Trabajadores (CTM) y la Confederación Nacional Campesina (CNC), ambos, además del

\footnotetext{
${ }^{19}$ Como ejemplo piénsese en gente como Carlos Salinas de Gortari, Manlio Fabio Beltrones, Emilio Gamboa Patrón, el actual presidente Enrique Peña Nieto. En provincia la lista es larga, entre esta, la familia Murat en Oaxaca, Madrazo en Tabasco; la familia Del Mazo en el Estado de México, etc. Entre los sindicatos, el SNTE es el más conectado con la clase política. La familia de la ex lideresa Elba Esther Gordillo, cuyas hijas, un nieto y un yerno son miembros de la clase política del país mediante senadurías y altos cargos en la burocracia.

${ }^{20}$ En el sector empresarial no ocurre lo contrario. La alta gerencia y la sucesión en el mando está siempre a cargo de un miembro varón de la familia y puede constatarse en los grupos poderosos como Carso y Bal.
} 
Sindicato Nacional de Trabajadores de la Educación (SNTE) eran fuentes del voto clientelar, y continúan siéndolo. No obstante, como Enrique Krauze señala, tanto De la Madrid como Carlos Salinas, tuvieron más de una oportunidad para realizar la reforma política tan necesaria en el país desde Porfirio Díaz (KRAUZE, 1997), pero como éste hiciera también, la democracia se pospuso y casi muere frente al imperativo de la reforma económica de Salinas. Aunque no se puede decir rotundamente que los tecnócratas eran antidemócratas, Miguel de la Madrid en principio estaba convencido de esta necesidad democrática (KRAUZE, 1997); Salinas quería hacer cambios democráticos en el PRI y por ende en su relación con el Ejecutivo (ALARCÓN, 1995), pero se toparon con la realidad y con los jerarcas del PRI, principalmente con los líderes delas corporaciones sindicales de la CTM y la CNC: tanto a De la Madrid como a Salinas les quedó claro que mientras ellos, como presidentes, no se metieran con estos sindicatos, obtendrían de éstos todo su apoyo (ALARCÓN, 1995). Ambos advirtieron que meterse con el PRI era perder el control del poder. Las reformas políticas electorales a las que ambos gobiernos se vieron obligados trajeron pérdidas electorales para el PRI en Chihuahua (1986) y Baja California (1989). En el caso del gobierno de Salinas, éste tuvo que atenerse a los "usos y costumbres" del Partido si quería salvar su proyecto económico y con éste sus ambiciones personales (ALARCÓN, 1995; HAMILTON, 2011; CAMP, 2006). De ahí que Centeno denominara al régimen mexicano como autoritario burocrático-electoral y a la administración salinista Salinostroika. El autor aduce que fue un periodo favorecido por varios factores externos e internos: un ambiente internacional propicio al neoliberalismo; un régimen político encarnado como una maquinaria autoritaria; un estado capturado por un sector poderoso (CENTENO, 1994), al que nosotros llamamos la elite del poder.

En el año 2000 vendría la derrota (casi) total del PRI frente al Partido Acción Nacional, consu candidato presidencial el gerente empresarial Vicente Fox. Todo lo anterior fue parte de los efectos que se desencadenaron el último año de la gestión de José López Portillo con la devaluación del peso en 1982, la inflación galopante, que trajeron descontento social entre las clases trabajadoras y dentro del propio sector empresarial, particularmente los del norte del país que empezaron a presionar al gobierno. Así también, reclamos de democratización interna de parte de una fracción de la elite priísta y sectores sociales. Todo ello aunado a casos de corrupción y nepotismo con Salinas, provocaron mayor desgaste en la legitimidad del sistema y 
en la credibilidad del gobierno. ${ }^{21}$ Esto trajo también el paulatino surgimiento de grupos cívicos pro democráticos que tendrían un papel clave a mediados y al final del sexenio de Salinas (HAMILTON, 2011).

Sabemos que las elites están conformadas por diversas facciones, por eso es arriesgado hablar de cohesión. Sin embargo, en lo que respecta al paradigma neoliberal, hay una clara conexión ideológica en la elite del poder (política y económica) que descansa en ostentar prestigio, en obtener beneficios económicos, personal y de grupo, y en ser partícipes del ejercicio del poder. En este punto Centeno argumenta que "Además de una congruencia ideológica, el liderazgo de las elites en casi todos los casos de revoluciones exitosas desde arriba comparten un fervor revolucionario que a veces parece rayar en la certeza/garantía megalómana en sus propias habilidades" (CENTENO, 1994, p.37).

Como hemos dicho antes, en el gobierno de Miguel de la Madrid se entrenaron en cargos relevantes Carlos Salinas, Jesús Silva Herzog Flores, Pedro Aspe. El recambio ideológico que tocó vivir a esta generación, exige vincularlo con el ejercicio del poder y con el expertise como dominación (SCOTT, 2008). Este autor argumenta que la 'restricción' existe donde la más alta autoridad $^{22}$ (quienes detentan los recursos) son capaces de influenciar a los subalternos, por tres vías: fuerza directa y represión, o mediante el ofrecimiento de estímulos a los subalternos. La otra vía, es la authoritativedomination o la dominación autorizada, mediante la creación o el establecimiento de un discurso. Así, "la autoridad existe donde la máxima autoridad influye en los subalternos mediante la persuasión arraigada en las obligaciones o compromisos institucionalizados, en las lealtades y la confianza que el mando y el expertise organizan" (SCOTT, 2008, p.31). "En todas las culturas los agentes internalizan valores que tienden a identificarse con aquellos que ocupan posiciones de dominación” (SCOTT, 2008, p.31). Dicha identificación se da y tiene los efectos según los valores que prevalezcan en cada cultura. Con esto queremos decir, que el expertise de los tecnócratas, que estudiaron en afamadas

\footnotetext{
${ }^{21}$ Al final del sexenio de Carlos Salinas varios hechos dieron la estocada a una administración que en sus últimos años gozaba de las mieles de un presumible prestigio nacional e internacional, pero dos fueron mortales: El surgimiento del Ejército Zapatista de Liberación Nacional el 1 de enero de 1994, y el asesinato del candidato a la presidencia por el PRI: Donaldo Colosio Murrieta el 23 de marzo de 1994. Véanse dos obras citadas en este trabajo: Enrique KrauzeLa presidencia imperial; y Nora Hamilton Mexico. Political, Social and EconomicEvolution.

${ }^{22}$ En lengua inglesa the principal es la más alta autoridad dentro de una institución, una organización o un grupo. Aquí yo lo entenderé como la elite del poder político, en principio. Dentro de esa elite, y en el contexto del régimen mexicano, la autoridad máxima es el presidente en el poder ejecutivo.
} 
universidades estadounidenses, fue un mensaje que caló inclusive dentro de una cúpula partidista tradicional. Esto aunado al eficiente desempeño que el grupo tuvo frente a los desenfrenados índices macroeconómicos que lograron estabilizar.

La cultura política dominante en el régimen político mexicano no hace halagüeño el porvenir si observamos que prevalecen valores plutocráticos y patrimonialistas en la historia del país. Son demasiados los casos de impunidad que indican que la ley se puede torcer o incumplir; se puede ser corrupto para fines personales porque no hay castigo ejemplar en los altos cargos, de ahí que según la posición de privilegio, es el grado de impunidad (CRUZ JIMÉNEZ, 2014; Raphael, 2014). Infortunadamente este es un marco de socialización y fuente de identificación e internalización de valores. La 'dominación autorizada' cuenta con legitimidad, entendida esta como la creencia de que el modelo de dominación es el adecuado, el correcto o el válido (HELD, 1989; BEETHAM, 1991 in SCOTT, 2008). De otra parte, el expertise de los tecnócratas y technopols entre las décadas de 1980 y 1990, sería clave en la 'dominación autorizada' que van a ejercer, este expertise se da en un caldo de cultivo de identificación e interiorización de valores que hizo posible la radicalidad de los cambios en la política económica, pero no así en la vida política en esos años.

\section{ALGUNAS CONSTANTES DE LAS ADMINISTRACIONES TECNOCRÁTICAS}

Las elites como problema de investigación, entendidas como tales siempre y cuando sean parte del ejercicio de poder político, económico (SCOTT, 2008) e ideológico, son aspectos casi siempre en interacción, que exigen se las estudie en cada época y en su contexto, como señaló MILLS (1956). La sociedad mexicana se funda en estructuras socioeconómicas y valores culturales de carácter jerárquico, patrimonialista y autoritario, están arraigadas en la clase política, en la clase empresarial y en la sociedad en general.

Aunque aquí no nos enfocamos en la relación entre el sector público y el privado, baste señalar que a lo largo de la historia del México postrevolucionario ambas esferas de poder, se refuerzan, se legitiman y se sostienen. Por más que se diseñen sofisticadas instituciones no hay instancia que aguante el debilitamiento que genera el abuso de poder de quien está al frente principalmente en el sector público. 
El arribo de los tecnócratas y los technopolsa las altas esferas del poder político trajo la reconciliación del Estado con la elite empresarial e industrial, asunto necesario sobre todo para el proyecto económico neoliberal. Dicha relación se había roto tras la nacionalización de la banca en 1982, a pocos meses de que José López Portillo concluyera su gobierno. También correspondió a éstos hacer los ‘ajustes' a la economía (1985-1986) conforme las condiciones impuestas por el Fondo Monetario Internacional (FMI) para hacer llegar 'dinero fresco' a la economía mexicana hundida por la crisis de la deuda. Al gobierno de Carlos Salinas le tocaría nuevamente en 1989 restructurar la deuda y el pago de servicios. No hay duda de las fuertes presiones de externas, primero con el Plan Baker, luego con el Plan Brady mediante el cual se impuso el Consenso de Washington, pero también es cierto que los doctores mexicanos en economía estaban convencidos de las políticas emanadas del FMI, de la sentencia thatcheriana "No hay alternativas".

Debido a la gravedad de la situación económica que heredó la administración de Miguel de la Madrid, su gobierno tenía que manejarse con tiento frente a múltiples presiones internas y externas. Sin embargo, el presidente se mantuvo impasible frente a coyunturas extraordinarias como el terremoto de 1985 y la nueva caída en los precios del petróleo, tan es así que su gobierno prefirió cumplir con las exigencias de los bancos internacionales acreedores en lugar de variar el rumbo económico. Las administraciones de Miguel de la Madrid y Carlos Salinas no titubearon frente a la difícil situación que trajeron los errores financieros, la corrupción y los vicios antidemocráticos en sus periodos, pero tampoco fueron coyunturas aprovechadas por estos para limpiar los vicios del régimen tradicional que tanto despreciaban.

La devastación de los terremotos de 1985 y la recaída en el precio del petróleo fueron oportunidades políticas para declarar la moratoria de la deuda o su renegociación en términos favorables para el país, pero no se hizo. Según Camacho Solís la decisión de entrar al GATT (General AgreementonTariffs and Trade), aun teniendo en cuenta las presiones externas para hacerlo, se dio a toda prisa por la urgencia de combatir, vía importaciones, la inflación interna: "Había prisa y los criterios ideológicos estaban dominando las decisiones gubernamentales" (CAMACHO SOLÍS, 2006, p.49), sin un plan previo para evitar el cierre de numerosas pymes y su efecto de pérdida de empleos (HAMILTON, 2011). Fue así que Camacho apuntó que en la administración de De la Madrid “el único criterio para decidir era el de la tijera” (CAMACHO 
SOLÍS, 2006, p.47). Es decir, los recortes continuos al presupuesto del gasto social en congruencia con el sumario del Consenso de Washington.

En cuanto a la intención de echar andar una agenda democrática, sobre todo en el periodo de Carlos Salinas, imperó la práctica del sine pro quod. Pamela Starr, quien fue profesora en el ITAM, argumentó que, "si bien hubo una expansión de prácticas democráticas durante la gestión de Salinas, éstas fueron controladas bajo dos acometidos: abrir el espacio político necesario para implementar sus reformas económicas y para bloquear la construcción de una democracia plena" (STARR, 1999, p.36), que como habíamos dicho antes, les colocaba entre la espada y la pared con respecto a los jerarcas del PRI. En esta línea, en el libro de Camacho hay muchas anécdotas (CAMACHO, 2006, p. 60,231, 233, 267), entre éstas las que tienen que ver con la alianza entre el PRI y el partido conservador Acción Nacional (PAN), para hacer una reforma política que entorpeciera los avances del PRD con Cuauhtémoc Cárdenas; ${ }^{23}$ o bien, cuando Salinas se negó a discutir el Tratado de Libre Comercio con la oposición, porque era suficiente el apoyo del PAN con el que contaba. Carlos Salinas, que inició su periodo presidencial bajo la sospecha de unas elecciones fraudulentas, su respuesta para dejar en el olvido tal circunstancia fue mediante golpes mediáticos como el encarcelamiento (sin juicio antes ni después) del líder del sindicato de la entonces paraestatal Petróleos Mexicanos, Joaquín Hernández Galicia; o el lanzamiento del programa populista Solidaridad (PRONASOL).

Sin embargo, también es de reconocer que desde que Salinas y su equipo (Aspe Armella) en la Secretaría de Programación y Presupuesto en el sexenio de De la Madrid se hicieron cargo del problema del déficit, que en 1987 había llegado a 150 mil millones de pesos, en 1991 éste se volvió superávit. En ese mismo año, a mitad del sexenio de Salinas, la inflación era menor al 20 por ciento (KRAUZE, 1997). Al mismo tiempo, fue en el gobierno de Salinas de Gortari donde se decidió concretar la dependencia de la economía mexicana a la de Estados Unidos; se orilló a empresarios a establecer alianzas con corporaciones estadounidenses (HAMILTON, 2011); a subrayar la subordinación con el capitalismo global comandado por este país: "Confiamos todo a las exportaciones y a la expansión de la economía estadounidense, a lo que otros hicieran y a lo

\footnotetext{
${ }^{23}$ Camacho narra cómo el PRI y el PAN aprobaron la reforma electoral de 1989 la que más bien fue una contrarreforma en la que quisieron impedir que el recién creado Partido de la Revolución Democrática (PRD), de izquierda en sus inicios, pudiera crecer (2006:233). En el mismo sentido de Starr, Camacho comenta en su libro que CSG para salvar su política económica permitió la reforma electoral de 1996 que dio autonomía al IFE: "Debía hacerlo o un estallido social le echaría a perder sus cálculos económicos” (2006:267).
} 
que habíamos hecho, más que a lo que debíamos hacer” (CAMACHO, 2006. p.61). Este miembro de la elite también se refiere al magistral manejo de las perspectivas, corolario del expertise, de parte de Carlos Salinas y Pedro Aspe: "sabían que su estrategia no duraría, lo único que les quedaba era jugar con las expectativas y convencer a los demás" (CAMACHO, 2006, p.53).

Así, la frase de The Economist "no entiende que no entiende" está presente en la vida política del país. En el régimen político mexicano se mira para otro lado aun cuando la realidad pone al gobierno frente a coyunturas, que son la oportunidad política para hacer cambios radicales a favor de la democracia y del estado de derecho. Sin embargo, la elección racional para estos ha sido primero proteger el fuero y salvaguardar los intereses personales y de grupo. En un análisis del periodo de Carlos Salinas y de Ernesto Zedillo, Pamela Starr plasma muy bien el proceder de este grupo, argumentando que la mayoría de los tecnócratas jamás tuvieron la intención de instrumentalizar el liberalismo político, sino únicamente de utilizar sus nuevas estrategias económicas para atrincherarse en el poder (STARR, 1999). Nosotros pensamos que los tecnócratas estaban y están realmente convencidos de su ortodoxia económica, miraron para otro lado cuando de realizarla y defenderla se trataba. Sin embargo, Camp converge con Starr: los tecnócratas mexicanos partían al extranjero para pulir sus conocimientos en política macroeconómica, no para modificar el rumbo del desarrollo político "no le veían mayor problema al modelo político" (CAMP, 2006, p. 240).

\section{A MODO DE CIERRE. ENTRADAS Y SALIDAS DE LA ELITE DEL PODER}

El tema central de este trabajo fue conocer la procedencia de los miembros de la elite del poder en los sexenios de Miguel de la Madrid y Carlos Salinas; cómo fue su entrada, salida o permanencia (directa o indirecta) en la elite del poder; los desafíos a los que se enfrentaron, sus logros, pero también las inercias que solaparon. De los 11 cargos principales, dos fallecieron: Miguel De la Madrid y Manuel Camacho. Hasta ahora solo uno de los cinco hijos de De la Madrid ha incursionado en la política desde el año 2000, se trata de Enrique de la Madrid Cordero actual secretario de Turismo en la administración de Peña Nieto (2012-2018). Carlos Salinas, tras la situación crítica con la que terminó su sexenio y el modo en que rompió con su sucesor Ernesto Zedillo, tuvo que salir de México hacia Irlanda, país con el que no hay tratado de extradición. Esta situación no impidió que Salinas fuera ajeno al mundo de la política en sus 
primeros años fuera de México, menos en los últimos. Salinas ha mantenido fuertes vínculos con personajes de la elite política tradicional imputados por corrupción. El primero es Emilio Gamboa Patrón, quien fue secretario Particular de De la Madrid cuando Salinas era secretario de Programación y Presupuesto (1982-1988). Se dice que Gamboa le favoreció frente a otros 'presidenciables' (CRUZ JIMÉNEZ, 2014). Por cierto, el hijo de éste, Pablo Gamboa Miner, incursionó en política desde los 22 años. Actualmente con 30 años es diputado Federal por Yucatán. Otro vínculo importante de Carlos Salinas es Manlio Fabio Beltrones, personaje polémico que entró al mundo de la política mexicana en 1973 con 21 años de edad y como secretario particular nada menos que de Fernando Gutiérrez Barrios, quien fungía entonces como subsecretario de Gobernación con De la Madrid. Sylvana es la hija única de Beltrones, también entró muy joven al mundo de la política, primero como diputada (por el PRI) federal suplente. En los últimos años Salinas ha normalizado su vida pública en México, inclusive opina sobre asuntos políticos ríspidos en los medios de comunicación, sobre todo a partir de la administración de Enrique Peña Nieto, de quien se sabe es una suerte de 'padrino político'. Dentro del gabinete de Peña Nieto está la sobrina de Salinas, Claudia Ruiz Salinas, de quien se dice es la consentida del ex presidente Carlos Salinas (CRUZ JIMÉNEZ, 2014), actualmente es secretaria general del PRI. Jesús Silva Herzog Flores a pesar de su abolengo salió de la vida política en el año 2000 tras perder en la campaña por la Jefatura de Gobierno de la ciudad de México en 2000. Sus descendientes no forman parte de la clase política. Miguel Mancera Aguayo, tras haber sido el primer gobernador del Banco de México en su calidad de entidad autónoma en 1994, se retiró de la vida pública en 1998. Pedro Aspe Armella a pesar de habérsele considerado en algún momento 'presidenciable' se retiró de la vida política, en 1996 fundó la consultoría Protego Asesores, es un pope en el ITAM, además de mentor de algunos funcionarios tecnócratas actuales como el otrora secretario de Hacienda Luis de Videgaray, hoy canciller. Una de sus hijas, Mónica Aspe, incursionó en la vida política en 1999 con el cargo de asesora del otrora Instituto Federal Electoral, actualmente es representante permanente en la Organización para la Cooperación y el Desarrollo Económico (OCDE). Rogelio Gasca Neri, fue un allegado a la política gracias a sus estudios de postgrado, después del gobierno de Salinas, fue director general de la paraestatal Comisión Federal de Electricidad de 1994 a 1999. Francisco Gil Díazse mantuvo en el poder político hasta 2006 con el gobierno panista de Fox (2000-2006), siendo secretario de Hacienda. 
Este ir y venir de los tecnócratas trasciende los partidos políticos, por ejemplo, los casos de Gil Díaz y el tecnócrata José Antonio Mead, ex alumno de Aspe Armella en el ITAM. Este último, empezó su carrera de político tecnócrata en el periodo de Zedillo (1994-2000), luego continuó en los dos sexenios panistas, con Vicente Fox y Felipe Calderón (2006-2012). Mead vuelve al gabinete priísta con Peña Nieto, su actual cargo es de secretario de Hacienda, inclusive se baraja como presidenciable en el PRI.

Ernesto Zedillo Ponce de León volvió a Estados Unidos como director del Centro para el Estudios de la Globalización de la Universidad de Yale. Como technopol, una vez concluido su periodo presidencial, se hizo consejero de diversas empresas de ese país como Protec and Gamble, Alcoa y UnionPacific. Esta última es concesionaria de Ferromex que fue privatizada durante su gobierno. Desde 2010 Zedillo es consejero del Grupo Prisa. Pareciera que los technopols no tienen necesidad de un cargo público, por lo menos es el único ex presidente que ha renunciado al a pensión vitalicia que por ley se concede y sus descendientes no están en la vida política, hasta ahora. José Córdoba Montoya se quedó en México a hacer negocios en el ámbito energético. Está vinculado con la alta política mexicana por medio de Guillermo Ortiz, gente de Zedillo.Jaime Serra Puchedespués de haber sido subsecretario de Hacienda con De la Madrid, luego titular de la otrora secretaría de Comercio y Fomento Industrial con Salinas, fue secretario de Hacienda con Zedillo. Al concluir esa Administración se retiró de la vida pública para dedicarse al mundo de la consultoría como presidente de SAI Consulting.

La labor de los tecnócratas de este periodo estuvo en sintonía con los signos de los tiempos que les tocó vivir y para los que fueron formados: reestructurar la economía de un país del tercer mundo de acuerdo con la doctrina del paradigma neoliberal. De los once tecnócratas enlistados, solo tres descendientes o parientes hacen carrera en la política. Teniendo en cuenta que dos han muerto, de los nueve restantes ninguno continúa en la vida política, aunque Carlos Salinas está detrás de bambalinas.

Otro resultado de este trabajo fue conocer el papel clave de otros agentes de cambio en la historia política y económica del país que inicia en las dos primeras décadas del siglo XX y concluye en los albores del siglo XXI. El rumbo socioeconómico del país desde entonces podría contarse, dejando momentáneamente a un lado al sector empresarial, a través del peso que tuvieron economistas e intelectuales mexicanos, entre estos Rodrigo Gómez, Daniel Cosío 
Villegas, Víctor Urquidi y Leopoldo Solís, educados en las afamadas universidades de Estados Unidos y de Europa en los años 30 y 40. Todos ellos bregaron por la formación de técnicos expertos en economía, materia que no existía entonces en el país, desde sus posiciones de mando, principalmente el Banco de México, donde diseñaron un programa de becas para hacer diplomados, maestrías y luego doctorados en el extranjero. Todos estos fueron mentores de quienes aparecen en la tabla.

Los pupilos de estos mentores concluyeron el proceso de hacer totalmente dependiente el desarrollo económico del país con la economía estadounidense, en sintonía con los intereses que vinculan al alto empresariado mexicano, principalmente con inversionistas norteamericanos. La situación socioeconómica actual en parte es hechura de los pupilos de los economistas liberales del Banco de México quienes, sin embargo, y a diferencia de muchos que aparecen en la tabla, sí conocían el contexto mexicano, sólo habría que ver el desempeño de los ministros de hacienda del periodo de desarrollo estabilizador (1950-1970) y antes de este (desde 1932) que fue más congruente con la realidad mexicana. Al parecer, los mentores no fueron capaces de exigir un ejercicio de adaptación crítico de esos conocimientos a sus pupilos y becarios, sólo se fomentó preparar técnicos dentro de doctrinas económicas que poco o nada tenían que ver con la realidad local.

Los tecnócratas llegaron a reformar la economía, sin meterse en líos con el régimen político, inclusive los cambios económicos radicales necesitaron de un régimen como el mexicano. Muchos salieron de la administración una vez concluido el periodo Salinas de Gortari, como Jaime Serra. Otros volvieron al gobierno a ocupar cargos todavía más importantes, como Gil Díaz. Los tecnócratas mexicanos encajan bien en la categoría de technopols, con alguna excepción, como Gil Díaz, estos no pretendieron mantenerse en el poder político, al menos no directamente, ya sea porque tenían compromiso previo con el sector privado o porque alguno surgió después de haber sido funcionario, eso sí, son una fiel expresión de la llamada puerta giratoria.

Paradójicamente (para los clásicos de las elites), la circulación se da y funciona en sociedades democráticas con checks and balances, pero en regímenes como el mexicano conduce a la permanencia de elites con valores antidemocráticos. La tesis de la decadencia de las elites, en concreto de la elite política en México, cobra relevancia en el momento actual del gobierno de 
Peña Nieto, cuya administración ha revelado el retorno de políticos tradicionales, como residuos de otra época, como el mismo presidente que, no obstante, representan una extraña mezcla de adhesión al paradigma neoliberal, pese a la revolución institucionalizada según el PRI.

\section{REFERENCIAS}

ALARCÓN OLGUÍN, V. El PRI en la presidencia de Carlos Salinas de Gortari (un balance sexenal). Estudios Políticos. México, p. 11-44, enero-marzo, 1995.

BABB, S. Del nacionalismo al neoliberalismo: El ascenso de los nuevos Money Doctors en México. En:Mato Daniel (coord.). Políticas de economía, ambiente y sociedad en tiempos de globalización. Caracas: Facultad de Ciencias Económicas y Sociales, Universidad Central de Venezuela, p. 155-172, 2005.

BURTON, M; GUNTHER, R; HIGLEY, J. Introduction: elites transformations and democraticregimes. En: Higley, J., Gunther, R. (Eds.). Elites and Democratic Consolidation in Latin America and Southern Europe. New York, CambrigdeUniversityPress, 1992.

CAMACHO SOLÍS, M .El desacuerdo nacional. México: Aguilar, 2006.

CAMP, R. Las elites del poder en México. México: Siglo XXI Editores, 2006.

CENTENO, M. Democracy Within Reason. Technocratic Revolution in Mexico. Penn.: The Pennsylvania State University, 1994.

CRUZ JIMÉNEZ, F. Las enseñanzas del profesor. Indagación de Carlos Hank González. Lecciones de poder, impunidad y corrupción. México: Océano, 1999. 
CRUZ JIMÉNEZ, F. Los juniors del poder. México: Planeta, 2014

DOMÍNGUEZ, J. Technopols: Freeing Politics and Markets in Latin America in the 1990s. Pennsylvania: Pennsylvania University Press, 1997.

GALINDO, A. Education of Mexican Government officials. Statistical Abstract of Latin America, 30, California: UCLA, 1993.

GIL DÍAZ, F. LeopoldoSolís, formador de economistas. En: Cárdenas, J. y Zabludovsky J. Leopoldo Solís y la realidad económica. México: FCE, p. 41-43, 2012.

HAMILTON, N. Mexico. Political, Social and Economic Evolution.Oxford, N.Y., Oxford University Pres, 2011.

JOIGNANT, A. El estudio de las Élites: un estado del arte. Serie de Políticas Públicas. Santiago de Chile: Universidad Diego Portales, 2009.

KNIGHT, A. Mexico's Elite Settlement: Conjunture and Consecuences.En: Higley J. y Gunther R. (eds). Elites and Democratic Consolidations in Latin America and Southern Europe, Cambridge University Press, p. 113-145, 1992.

KRAUZE, E. La presidencia imperial. México, Tusquets Editores México, 1997.

MILLS, C. La elite del poder. México: FCE, 1956.

NIETO, N. La socialización de las elites políticas mexicanas a través de la corrupción. Análisis Político. (71). p. 165-181, 2011.

PARETO, V. Forma y equilibrio sociales. Madrid: Alianza Editorial, 1980. 
Verónica de la T. Oropeza Cadernos Prolam/USP, v.16, n.30, p.42-72, jan./jun.2017

RAPHAEL, R. Mirreynato. La otra desigualdad. México: Temas de Hoy, 2014.

ROUSSEAU, I. La SPP y la dinámica de constitución de un equipo. Foro Internacional, v. XXXVIII. p. 302-339, 1998.

SASSEN, S. Una sociología de la globalización. Análisis político, n. 61, p. 3-27, 2007.

SCOTT, J. Modes of power and the re-conceptualization of elites. Sociological Review, p. 27-43, 2008.

SOLÍS, L. Semblanzaautobiográfica. En: Cárdenas, J. y Zabludovsky J. LeopoldoSolís y la realidadeconómica. México: FCE, p. 15-24, 2012.

STARR, K. Monetary Mismanagement and Inadvertent Democratization in Technocratic Mexico. Studies in Comparative International Development, v. 33, Issue 4, p. 35-65, 1999.

TEICHMAN, J. Privatization and political change in Mexico.Pitt, PA: University of Pittsburgh Press, 1995.

TEICHMAN, J. The politics of Freeing Markets in Latin America.Chile, Argentina $y$ Mexico,Chapel Hill: University of North Carolina, 2001.

Recebido em 16/06/2017.

Aceito em 09/11/2017. Publicado em 29/12/2017.

DOI: 10.11606/issn.1676-6288.prolam.2017.133691

ISSN: $1676-6288$ 